Editorial

\title{
Improvement and Application of Zirconium Alloys
}

\section{Wen Qin}

Department of Mechanical Engineering, University of Saskatchewan, Saskatoon, SK S7N 5A9, Canada; weq565@mail.usask.ca or wenqin68@gmail.com; Tel.: +1-306-9667752

Received: 24 September 2018; Accepted: 29 September 2018; Published: 3 October 2018

\section{Introduction and Scope}

Zirconium ( $\mathrm{Zr}$ ) alloys have attracted special attention because of their application in various fields such as nuclear cladding materials, biomedical implant materials and shape memory materials. This Special Issue mainly aims to address the corrosion and the surface modification of $\mathrm{Zr}$ alloys, pellet-cladding interaction and irradiation-induced damage. It also examines $\mathrm{Zr}$ alloys as biomedical materials and shape memory materials.

\section{Contributions}

Corrosion resistance and mechanical properties are two important factors in designing nuclear cladding materials. The corrosion resistance and mechanical strength of $\mathrm{Zr}$ alloys, to a large extent, depend on alloying elements. The paper by Zhang et al. [1] provides an insight into the influence of $\mathrm{Sn}$ element on the properties of $\mathrm{Zr}$-based alloy. Based on this work, a new low-Sn Zr alloy series of $\mathrm{Zr}-0.25 \mathrm{Sn}-0.36 \mathrm{Fe}-0.11 \mathrm{Cr}-x \mathrm{Nb}$ was developed. This type of alloy shows an excellent corrosion resistance and high strength, and might be a candidate for use in nuclear reactors. The corrosion resistance of $\mathrm{Zr}$ alloys is also related to the surface properties of alloys. The paper by Obrosov et al. [2] used plasma immersion ion implantation to modify the surface properties of $\mathrm{Zr}-1 \mathrm{Nb}$ alloy, and studies the influence of Ti implantation on surface morphology, oxidation rate, and phase structure of $\mathrm{Zr}-1 \mathrm{Nb}$ alloy. Pellet-cladding interaction can lead to the accelerated failure of fuel channels systems in nuclear reactors. The paper by Zhou and Zhou [3] used the CityU Advanced Multiphysics Nuclear Fuels Performance with User-defined Simulations (CAMPUS) code to study the thermophysical performance and solid mechanics behavior of $\mathrm{UO}_{2}-36.4 \mathrm{vol} \% \mathrm{BeO}$ fuel pellets cladded with Zircaloy, $\mathrm{SiC}$, and $\mathrm{FeCrAl}$, and Zircaloy cladding materials coated with $\mathrm{SiC}$ and $\mathrm{FeCrAl}$, and compared the mechanical interactions of fuel and cladding materials. The stability of materials under high-energy irradiation is crucially important for the safety of nuclear reactors. The paper by Dong et al. [4] studied the precipitate stability of $\mathrm{Zr}-2.5 \mathrm{Nb}-0.5 \mathrm{Cu}$ alloy under heavy ion irradiation, the effects of the surrounding microstructure on the precipitate stability, and the irradiation-induced alloying element redistribution.

$\mathrm{Zr}$ alloys can also be used as biomedical materials and have an important application in magnetic resonance imaging due to its relatively small magnetic susceptibility. The paper by Ashida et al. [5] studied the influence of different thermomechanical process on the mechanical properties and magnetic susceptibility of the $\mathrm{Zr}-1 \mathrm{Mo}$ alloy. The paper by Sun et al. [6] used the powder-bed fusion process to prepare a low-magnetic $\mathrm{Zr}-1 \mathrm{Mo}$ alloy, and studied the effects of the process parameters on surface morphology, pore distribution, and hardness of $\mathrm{Zr}-1 \mathrm{Mo}$ alloys.

In addition, equiatomic Zr-Pd alloy can be used as shape memory materials with high transformation temperature. The paper by Matsuda et al. [7] reconstructed the phase diagram of a near equiatomic $\mathrm{Zr}-\mathrm{Pd}$ binary system and determined the exact eutectoid and peritectoid temperatures.

Funding: This research received no external funding. 
Conflicts of Interest: The author declares no conflict of interest.

\section{References}

1. Zhang, R.Q.; Jiang, B.B.; Pang, C.; Dai, X.; Sun, Y.D.; Liao, W.; Wang, Q.; Dong, C. New low-Sn Zr cladding alloys with excellent autoclave corrosion resistance and high strength. Metals 2017, 7, 144. [CrossRef]

2. Obrosov, A.; Sutygina, A.N.; Manakhov, A.; Bolz, S.; Weiß, S.; Kashkarov, E.B. Oxidation behavior of Zr-1Nb corroded in air at $400{ }^{\circ} \mathrm{C}$ after plasma immersion titanium implantation. Metals 2018, 8, 27. [CrossRef]

3. Zhou, W.; Zhou, W.Z. Thermophysical and mechanical analyses of $\mathrm{UO}_{2}-36.4 \mathrm{vol} \% \mathrm{BeO}$ fuel pellets with zircaloy, $\mathrm{SiC}$, and FeCrAl claddings. Metals 2018, 8, 65. [CrossRef]

4. $\quad$ Dong, Q.S.; Yao, Z.W.; Wang, Q.; Yu, H.B.; Kirk, M.A.; Daymond, M.R. Precipitate stability in a Zr-2.5Nb-0.5Cu alloy under heavy ion irradiation. Metals 2017, 7, 287. [CrossRef]

5. Ashida, M.; Morita, M.; Tsutsumi, Y.; Nomura, N.; Doi, H.; Chen, P.; Hanawa, T. Effects of cold swaging on mechanical properties and magnetic susceptibility of the $\mathrm{Zr}-1 \mathrm{Mo}$ alloy. Metals 2018, 8, 454. [CrossRef]

6. Sun, X.H.; Zhou, W.W.; Kikuchi, K.; Nomura, N.; Kawasaki, A.; Doi, H.; Tsutsumi, Y.; Hanawa, T. Fabrication and characterization of a low magnetic $\mathrm{Zr}-1 \mathrm{Mo}$ alloy by powder bed fusion using a fiber laser. Metals 2017, 7, 501. [CrossRef]

7. Matsuda, M.; Nishiura, T.; Yamamuro, T.; Nishida, M. Phase diagram of near equiatomic Zr-Pd alloy. Metals 2018, 8, 366. [CrossRef]

(C) 2018 by the author. Licensee MDPI, Basel, Switzerland. This article is an open access article distributed under the terms and conditions of the Creative Commons Attribution (CC BY) license (http:/ / creativecommons.org/licenses/by/4.0/). 